\title{
Developmental psychopathology: Some thoughts on its evolution
}

This is the inaugural issue of Development and Psychopathology. I am honored to serve as the Editor of this new journal, as I consider its publication to be yet another step in the growth of the discipline of developmental psychopathology. While the historial roots of this field can be traced to the great systematizers of psychology, psychiatry, and the neurosciences, its emergence as an autonomous area of scientific inquiry did not occur until the 1970s (Cicchetti, 1984). While there are multiple reasons for this delay, factors related to the need for a solid foundation of normal development upon which to build and the unfortunate history of separation between academic and clinical endeavors are at least partially responsible (Cicchetti, 1984, in press-a; Santostefano, 1978). In view of its relatively recent emergence, the excitement generated by theoreticians and researchers who have directed their energies toward defining the parameters of this field are truly noteworthy. In fact, it is a credit to the integrative and multidisciplinary nature of developmental psychopathology that such a wealth of interest has been spawned and a significant corpus of theory and data established.

Although detailed reviews of the underlying principles and applications of developmental psychopathology have been writ-

I would like to thank Sheree Toth for her comments and feedback and Victoria Gill for typing this manuscript. In addition, I wish to acknowledge the support which I received from the John $D$, and Catherine $T$. MacArthur Foundation Network on Early Childhood and the Spunk Fund, Inc., during the preparation of this editorial. - D.C. ten (see, for example, Achenbach, in press; Cicchetti, in press-a; Nannis \& Cowan, 1988; Rutter, 1986; Rutter \& Garmezy, 1983; Sroufe \& Rutter, 1984; Zigler \& Glick, 1986), this editorial will briefly summarize the central tenets of this discipline. First and foremost, developmental psychopathology is committed to the application of developmental principles to the study of high risk and deviant populations. Inherent within this framework is a focus on the importance of applying our knowledge of normal development to the study of atypical populations and, likewise, recognition of the value in examining abnormality in order to enhance our understanding of normal development. It is, however, the goal of developmental psychopathology to move beyond mere identification of risk factors for and precipitants of psychopathology to understanding the mechanisms and processes by which such factors lead to the emergence of a disorder (Rutter, 1988). A major component of this necessitates viewing behavior and development within a social context and, as such, recognizing the transactional nature of interactions. For example, disordered behavior is not conceptualized as a static condition but is viewed as being in dynamic transaction with both intra- and extra-organismic forces (Cicchetti \& Schneider-Rosen, 1986). As this brief discussion begins to elucidate, developmental psychopathology is a comprehensive approach which strives to integrate elements derived from the fields of developmental psychology, clinical psychology and psychiatry, epidemiology, sociology, and both the 
physiological sciences and neurosciences (Cicchetti, in press-a). Developmental psychopathology serves as a forum in which these seemingly diverse approaches of inquiry can be integrated into a cohesive format of research. In order to achieve this ambitious goal, it is important to explore developmental continuities and discontinuities across the lifespan (see, for example, Main, Kaplan, \& Cassidy, 1985; Quinton \& Rutter, in press; Robins, 1966; Rutter, 1987; Sroufe, 1983; Zigler \& Glick, 1986). While clearly no one study can incorporate all of these components, the consensus which can emerge from diverse research projects bound by these principles can result in significant progress in our knowledge of normal and abnormal development.

With this as a theoretical base, questions may arise as to how developmental psychopathology differs from other fields of inquiry - specifically, developmental psychology, clinical psychology, and psychiatry. Perhaps most importantly, developmental psychopathology focuses on the interplay between normal and abnormal development. While developmental psychologists are interested largely in normal development as opposed to the focus on risk conditions and psychopathology espoused by clinical psychologists and psychiatrists, developmental psychopathologists believe that knowledge of each is necessary and therefore warrants equal attention. Accordingly, the developmental psychopathologist is concerned with the etiology, developmental course, precursors and sequelae of disordered behavior, as well as with its relation to non-disordered behavior (Sroufe \& Rutter, 1984). Moreover, developmental psychopathologists are interested in ascertaining the internal and external factors that promote or inhibit the development of competence or resiliency in children and adults (Cowen \& Work, 1988; Garmezy, 1987; Garmezy \& Rutter, 1983; Masten, in press; Rolf, Masten, Cicchetti, Neuchterlein, \& Weintraub, in press). In order to comprehend fully these nuances, development from infancy through adulthood must be explored. While developmental psychopathology does contain aspects of many disciplines, it is unique in its very efforts to synthesize this diversity.

It is in this tradition which Development and Psychopathology was conceptualized. The need for this journal is two-fold. First, and perhaps most obviously, it will serve as a forum for theoreticians and researchers to present work which has been conceived within this framework. The multi-disciplinary origins of developmental psychopathology also call for contributions from researchers in diverse fields, thereby enabling an audience outside of one's own field to have access to data which is pertinent to developmental psychopathology (Cicchetti, in press-a). This relates to the second point, which involves the increased visibility which this journal will impart to the principles inherent in developmental psychopathology. Because this is such an integrative approach, the potential impact of this journal to generate increased research interest and productivity within this discipline is compelling. Moreover, it is the field of developmental psychopathology which holds the promise for spanning the dualisms which have separated academic research from clinical practice for so long. By recognizing the mutual benefit which can be gained from an integration of knowledge derived from applied work and scientific inquiry, investigators traditionally concerned with only one of these areas can expand their knowledge bases. In fact, research, training, prevention, intervention, and social policy all can be improved by the incorporation of a developmental perspective and recognition of the role of deviance within the normal developmental sequence (Achenbach, in press; Cicchetti, in press-b; Cicchetti \& Toth, in press; Nannis \& Cowan, 1988; Rolf, 1985; Wald, 1980; Wald, Carlsmith, \& Leiderman, 1988).

It is therefore with great enthusiasm for the vast potential of this discipline and with a commitment to its advancement that I introduce the first issue of Development and Psychopathology. The journal will be pub- 
lished quarterly, and I anticipate that the content of the journal will mirror the growth of the discipline as a whole. It is critical that a breadth of orientations and professional disciplines be represented in the journal, and I encourage submissions from theoreticians, researchers, and clinicians of all disciplines, with the only limiting factor being attention to the developmental perspective. Because we are defining a new discipline, the Deputy Editor, Barry Nurcombe, the Associate Editors, the

Rochester, New York

April 1989

\section{References}

Achenbach, T. (in press). What is "developmental" about developmental psychopathology? In J. Rolf, A. Masten, D. Cicchetti, K: Neuchterlein, \& S. Weintraub (Eds.), Risk and protective factors in the development of psychopathology. New York: Cambridge University Press.

Cicchetti, D. (1984). The emergence of developmental psychopathology. Child Development, 55, 1-7.

Cicchetti, D. (in press-a). An historical perspective on the discipline of developmental psychopathology. In J. Rolf, A. Masten, D. Cicchetti, K. Neuchterlein, \& S. Weintraub (Eds.), Risk and protective factors in the development of psychopathology. New York: Cambridge University Press.

Cicchetti, D. (jn press-b). The organization and coherence of socioemotional, cognitive, and representational development: Illustrations through a developmental psychopathology perspective on Down syndrome and child maltreatment. In R. Thompson (Ed.), Nebraska Symposium on Motivation. Vol. 36. Socioemotional development. Lincoln: University of Nebraska Press.

Cicchetti, D., \& Schneider-Rosen, K. (1986). An organizational approach to childhood depression. In M. Rutter, C. Izard, \& P. Read (Eds.), Depression in young people: Clinical and developmental perspectives (pp. 71-134). New York: Guilford.

Cicchetti, D., \& Toth, S. (in press). The making of a developmental psychopathologist. In J. Cantor, C. Spiker, \& L. Lipsitt (Eds.), Child behavior and development: Training for diversity. Norwood, NJ: Ablex.

Cowen, E. L., \& Work, W. C. (1988). Resilient children, psychological wellness and primary prevention. American Journal of Community Psychology, 16, 591-607.

Garmezy, N. (1987). Stress, competence, and development. American Journal of Orthopsychiatry, 57, 159-174.

Garmezy, N., \& Rutter, M. (Eds.). (1983). Stress, coping and development in children. New York: McGraw-Hill. distinguished members of the Editorial Board, and myself all are dedicated to working closely with potential contributors to help conceptualize submissions within this perspective. As a new endeavor, the success of this journal, as well as the advancement of developmental psychopathology, is dependent upon our commitment to realizing the potential of the field. I invite you to become an active participant in this process.

\section{Dante Cicchetti} Editor

Main, M., Kaplan, N., \& Cassidy, J. C. (1985). Security in infancy, childhood and adulthood: A move to the level of representation. In I. Bretherton \& E. Waters (Eds.), Growing points of attachment theory and research. Monographs of the Society for Research in Child Development, 50 (1-2, Serial No. 209), 66-104.

Masten, A. (in press). Resilience in development: Implications of the study of successful adaptation for developmental psychopathology. In D. Cicchetti (Ed.), Rochester Symposium on Developmental Psychopathology: Vol. 1. Hillsdale, NJ: Erlbaum.

Nannis, E., \& Cowan, P. (Eds.). (1988). Developmental psychopathology and its treatment. San Francisco: Jossey-Bass.

Quinton, D., \& Rutter, M. (in press). Parental breakdown: The making and breaking of intergenerational links. Aldershot, England: Gower.

Robins, L. (1966). Deviant children grown up. Baltimore: Williams \& Wilkins.

Rolf, J. (1985). Evolving theories and methods for preventive research with children. Journal of Consulting and Clinical Psychology, 53, 631-646.

Rolf, J., Masten, A., Cicchetti, D., Neuchterlein, K., \& Weintraub, S. (Eds.). (in press). Risk and protective factors in the development of psychopathology. New York: Cambridge University Press.

Rutter, M. (1986). Child psychiatry: The interface between clinical and developmental research. Psychological Medicine, 16, 151-160.

Rutter, M. (1987). Continuities and discontinuities from infancy. In J. Osofsky (Ed.), Handbook of infancy (2nd ed.) (pp. 1256-1296). New York: Wiley.

Rutter, M. (1988). Epidemiological approaches to developmental psychopathology. Archives of General Psychiatry, 45, 486-495.

Rutter, M., \& Garmezy, N. (1983). Developmental psychopathology. In E. M. Hetherington (Ed.), Carmichael's manual of child psychology, (Vol. 4): Social and personality development (pp. 775-912). New York: Wiley.

Santostefano, S. (1978). A bio-developmental ap- 
proach to clinical child psychology. New York: Wiley.

Sroufe, L. A. (1983). Infant-caregiver attachment and patterns of adaptation in preschool: The roots of maladaptation and competence. In M. Perlmutter (Ed.), Minnesota Symposium in Child Psychology: Vol. 16 (pp. 14-83). Minneapolis: University of Minnesota.

Sroufe, L. A., \& Rutter, M. (1984). The domain of developmental psychopathology. Child Development, 83, 173-189.
Wald, M. (1980). Thinking about public policy toward abuse and neglect of children: A review of "Before the best interests of the child." Michigan Law Review, 78, 645-693.

Wald, M., Carlsmith, J., \& Leiderman, P. H. (1988). Protecting abused and neglected children. Stanford: Stanford University Press.

Zigler, E., \& Glick, M. (1986). A developmental approach to adult psychopathology. New York: Wiley. 